\title{
The Emergence of Defined Subunit Vaccines for the Prevention of Leishmaniasis
}

\author{
Malcolm S. Duthie • Steven G. Reed
}

Published online: 27 June 2014

(C) Springer International Publishing AG 2014

\begin{abstract}
Infection with Leishmania parasites can cause disease across a range of clinical manifestations and outcomes. Given the practical difficulties in maintaining vector control programs, vaccination is likely the only way in which the sustained reduction or elimination of the leishmaniases can be achieved. In this review, we focus on the development of second-generation vaccines with emphasis on defined subunit vaccines using recombinant expression techniques. We highlight particular antigens that have provided protection in animal models, and discuss methods, such as inclusion in chimeric fusion proteins and use of appropriate adjuvants, that are likely required to transition these into clinically-relevant candidates. We also outline the alternative strategies, such as attenuated parasites, DNA vaccination, and use of sand fly proteins, that are being proposed.
\end{abstract}

Keywords Leishmania · Protein · Adjuvant · Protozoa · Vaccine $\cdot$ Protozoa

\section{Introduction}

The leishmaniases are a family of diseases, caused by infection with various Leishmania species parasites, that cause human suffering on a global scale. Estimates are that there are 12 million current cases, with an additional 2 million cases each year and a population of approximately 350 million people at risk of infection in endemic areas. The geographic distribution of each Leishmania species determines the disease presentation in each region. Cutaneous leishmaniasis (CL) can be caused by several Leishmania species that are

M. S. Duthie $(\bowtie) \cdot$ S. G. Reed

Infectious Disease Research Institute, 1616 Eastlake Ave A, Suite 400, Seattle, WA 98102, USA

e-mail:mduthie@idri.org endemic in the tropics and neotropics, where it manifests as a spectrum of clinical presentations ranging from small cutaneous nodules to gross mucosal tissue destruction (mucocutaneous leishmaniasis; ML) [1]. Visceral leishmaniasis (VL) is the most severe form and is fatal if left untreated. VL cases in South Asia and Africa are caused by infection with L. donovani, while in the Mediterranean, the Middle East, Latin America and other parts of Asia it results from infection with $L$. infantum [2]. Mainly observed in Sudan and India, post-kala-azar dermal leishmaniasis (PKDL) is a posttreatment complication in a subset of recovered VL patients that is characterized by a macular, maculopapular, and nodular rash [3]. Although improved drug regimens for the treatment of VL are becoming available [4-8], this requires the diagnosis and prompt treatment of active cases. Vaccination could provide not only long-term protection against infection/ disease but also impact potential reservoirs to reduce transmission. Thus, widespread vaccination is likely the only way in which elimination of leishmaniases can be achieved.

\section{Historical Vaccines for the Prevention of Leishmaniasis}

Vaccination against Leishmania species was occurring empirically for centuries in the form of leishmanization, a practice that involved the inoculation of virulent $L$. major parasites into hidden areas of the skin. Leishmanization, which continued until relatively recently in many regions, typically induced mild infection and subsequent immunity against further naturally occurring infection [9]. However, the occasional development of progressive infection and disease has led to leishmanization being abandoned as unsafe. The practice did, however, demonstrate the potential for successful vaccination against Leishmania parasites if responses can be harnessed appropriately. Even as recently as the last decade, vaccine trials have been conducted using whole, killed or 
inactivated parasites [10-18]. Probably because this strategy involves the use of crude preparations that are very difficult to standardize, clinical results have generally been inconsistent and these vaccines were typically not protective.

Understanding how responses that can clear or restrict the parasites are initiated and evolve during the protective immune response against Leishmania parasites is highly informative in the rationale design and development of more refined vaccines capable of promoting protection without detrimental side effects. Basic research has provided significant insight as to how to induce protective immune responses against Leishmania species [19]. Leishmania parasites reside within antigen-presenting cells, mainly macrophages, and these cells play a pivotal role in determining the quality of the adaptive immune response. The seminal discovery of the $\mathrm{T}$ helper (Th)1/Th2 paradigm of CD4 T-cell response was aided by studies using CL-resistant and CL-susceptible inbred mouse strains [20-22], and protection studies have accordingly demonstrated the Th1-dependence of effective immunity against Leishmania, particularly against CL. In turn, the Leishmania-infected cells require and can respond to T-cellderived cytokines to activate anti-parasitic mechanisms such as inducible nitric oxide synthase, nitric oxide and interferon gamma (IFN $\gamma$ ) production. Importantly, appropriate antigen-specific Thl responses also correlate with protection against $\mathrm{CL}$ in humans. Thus, despite there being many more complexities in the mechanisms responsible for acquired immunity, a core hypothesis across Leishmania vaccine development programs is that a strong, long-lasting Th1 cell response is necessary to reduce parasite replication/survival and preventing disease.

\section{The Here and Now of Vaccines for the Prevention of Leishmaniasis}

\section{Toward Defined Subunit Vaccines}

\section{Antigen Candidates}

While crude extraction or purification of proteins from pathogens was used for a long time to derive potential vaccine candidates, the ready availability of genetic data over the last two decades has led to the evolution of candidate identification through bioinformatic selection and recombinant production methods Fig. 1. Molecular biology tools are now routinely using to select candidates with perceived desirable features (i.e. membrane-spanning domains versus secreted proteins) and anticipated acceptable safety profiles (i.e. low homology to human genes).

A plethora of recombinant proteins have been investigated as Leishmania vaccine antigen candidates in animal models and new candidates are regularly being proposed (Table 1).
How these antigens are prepared and/or formulated can dramatically impact their use. For example, immunization with only native Parasite Surface Antigen (PSA)-2 polypeptides, but not other forms, protected mice against infection [46-50]. Among the many recombinant proteins that have elicited protection, the surface expressed glycoprotein leishmaniolysin (gp63) generated promising findings from animal models following delivery by numerous immunization regimens; however, those results were overshadowed by mostly negative T-cell responses in humans [51, 52]. Although protective efficacy of Leishmania homolog for receptors of activated $\mathrm{C}$ kinase (LACK) has been demonstrated mainly in the L. major model, LACK has failed to protect against experimental VL [23, 24]. In contrast, recombinant nucleoside hydrolase $(\mathrm{NH})$ vaccinated $\mathrm{BALB} / \mathrm{c}$ mice demonstrate a significant decrease in parasite burden following challenge with $L$. infantum, L. mexicana and $L$. major $[25,26]$. We identified that the sterol 24-c-methyltransferase (SMT) protein is similarly capable of protecting against challenge with both CL- and VL-causing parasites [27, 28]. Despite the large number of recombinant proteins that have been suggested as vaccine antigen candidates, to date very few have advanced to clinical trials.

\section{Chimeric Fusion Proteins}

Analogous to the use of whole parasites, the current state-ofthe-art in vaccinology is to simultaneously provide multiple antigen candidates to expand the likelihood that an immunized individual will recognize and respond to at least some of the included epitopes. Recombinant proteins have been used for years in standard immunization schedules (e.g. hepatitis B surface antigen [HBsAg] for hepatitis B virus) and chimeric fusion proteins representing many antigens in a single product have advanced to clinical trials for several indications [53-57]. Using genetic information on sequence conservation among Leishmania species, selection criteria for the inclusion of genes within fusion constructs can also consider the potential for cross-species protection and even the ability to protect against the various clinical presentations of leishmaniasis. For practical considerations, such as the ability to be expressed and purified as a single product (rather than multiple individual proteins to be combined later, all of which would require full GMP production and evaluation), and based on the design of the construct, expression can be driven to high levels even for components that are difficult to produce as single, nonfused proteins, fusion proteins have great appeal Fig. 1.

Fusion proteins may also enhance the levels of protection that can be elicited. As an example, when used alone the L. major cysteine proteinases (Type I [CPB] and Type II [CPA]) induce only partial protection against $L$. major infection in BALB/c mice [58]. However, relative to the single proteins, greater protection was afforded when a cocktail of 
Table 1 A representative sampling of antigens that have been proposed as vaccine antigen candidates for leishmaniasis

\begin{tabular}{|c|c|c|c|}
\hline Antigen & Full given name & Parent Leishmania species & References \\
\hline LACK & $\begin{array}{l}\text { Leishmania homologue for receptors of } \\
\text { activated } \mathrm{C} \text { kinase }\end{array}$ & major & {$[23,24]$} \\
\hline NH & Nucleoside hydrolase & infantum & {$[25,26]$} \\
\hline SMT & Sterol 24-c-methyltransferase & infantum & {$[27,28]$} \\
\hline $\mathrm{A} 2$ & Amastigote-specific A2 proteins & donovani & {$[29]$} \\
\hline ORFF & Open-reading frame gene from the LD1 locus & donovani & {$[30]$} \\
\hline LiP0 & Acidic ribosomal protein $\mathrm{P} 0$ & infantum & {$[31]$} \\
\hline PFR-2 & Paraflagellar rod protein 2 & mexicana & {$[32]$} \\
\hline PPG & N-terminal domain of proteophosphoglycan & donovani & {$[33]$} \\
\hline MAPK10 & MAP kinase 10 & major & {$[34]$} \\
\hline LeIF-2 & Elongation factor-2 protein & donovani & {$[35]$} \\
\hline TDR1 & Thiol-dependent reductase 1 & infantum & {$[36]$} \\
\hline $115 \mathrm{kDa}$ & $115 \mathrm{kDa}$ serine protease & donovani & {$[37]$} \\
\hline LmL5 & Ribosomal protein & major & {$[38]$} \\
\hline rLdAld & Aldolase & donovani & [39] \\
\hline rLdEno & Enolase & donovani & [39] \\
\hline CyP1 & Cyclophilin protein 1 & infantum & {$[40]$} \\
\hline LPG3 & Lipophosphoglycan & major & {$[41 \cdot]$} \\
\hline $\mathrm{HbR}$ & Hemoglobin receptor & donovani & {$[42 \bullet]$} \\
\hline gGCS & Gamma-glutamyl cysteine synthetase & donovani & {$[43,44 \bullet]$} \\
\hline TPR & Trypanothione reductase & donovani & {$[45]$} \\
\hline
\end{tabular}

CPA and CPB containing DNA constructs was used. Following fusion of the genes and expression of the CPA/B hybrid protein, mice vaccinated with $\mathrm{CPA} / \mathrm{B}$ exhibited a delay in the expansion of L. major-induced lesion size compared with control groups [59].

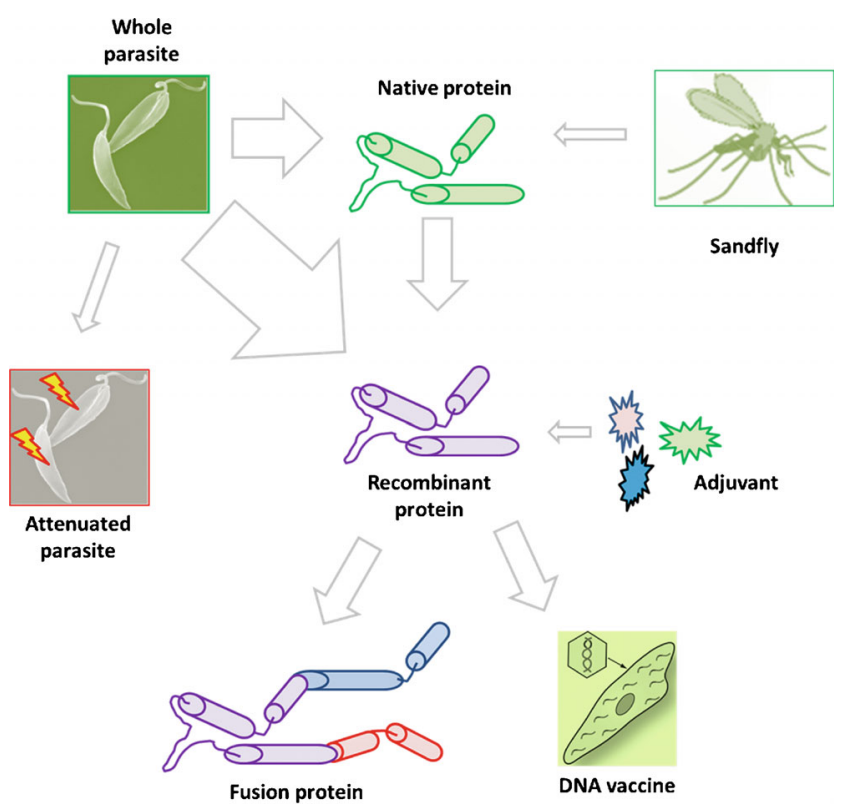

Fig. 1 Schematic representation of the evolution of vaccine strategies for leishmaniasis. Each arrow is sized with the intent of reflecting the degree of transition that has occurred between the respective areas
We have generated multiple fusion proteins and evaluated their protective efficacy in experimental models. Of these, to date three have advanced to clinical trials. The first to progress was a recombinant tri-fusion polyprotein comprising antigens thiol-specific antioxidant (TSA), L. major stress-inducible protein 1 (LmSTI1), and Leishmania elongation initiation factor (LeIF) that was generated and named L111f. Immunization of BALB/c mice elicited a predominant Th1 immune response characterized by in vitro lymphocyte proliferation, IFN $\gamma$ production, and $\operatorname{IgG} 2 \mathrm{a}$ antibodies with little, if any, interleukin (IL)-4. Moreover, L111f formulated with monophosphoryl lipid A-stable emulsion (MPL-SE) conferred immunity to leishmaniasis for at least 3 months. The L111f polyprotein has been slightly modified, by removing the His tag, to render L110f which retains all of the antigenic and protective activity [60]. The L111f and L110f antigens have been further developed as therapeutic candidates [61] and have been used in numerous clinical trials for various presentations of leishmaniasis [62].

The second fusion protein that we have advanced is a tetrafusion named KSAC. KMP-11, SMT, A2, and CPB have all been demonstrated to individually confer protection in different disease models of VL, and each of these components is represented in KSAC [27-29, 63-66]. When the KSAC polyprotein was generated and delivered with adjuvant, we discovered that in our VL model, two of the individual antigens, SMT and CPB, stimulated the majority of the protective 
response. However, because KMP-11 was shown to be an effective antigen when delivered as DNA, and because A2 has shown some degree of efficacy in dogs, these antigens were retained [64, 67]. KSAC induced protection equal to L110f in our mouse protection models of CL [68 $]$ and, more recently, was demonstrated to be effective in protecting mice against L. major using a sand fly challenge [69•].

The most recent polyprotein we have advanced is a difusion pairing $\mathrm{NH}$ with SMT. This fusion protects against experimental VL and its safety was recently evaluated in a phase I trial (unpublished data).

\section{Emerging Alternatives}

\section{Live-Attenuated Vaccines}

Building on the experience with leishmanization and the prior use of killed parasites, a variety of studies have now evaluated the ability of Leishmania attenuated strains to protect against subsequent challenge with virulent parasites. Defined genetic alteration to generate avirulent Leishmania species theoretically permits mimicry of natural infection and delivery of a complete spectrum of antigens to the antigen-presenting cells to provide a broad protective response.

L. major phosphomannomutase (PMM)-deficient mutants were able to protect $L$. major-susceptible BALB/c mice against infection, most likely due to the suppressed IL-10 and IL-13 production early during infection, and increased magnitude of $\mathrm{T}$-cell responses [70]. Inoculation with dihydrofolate reductase thymidylate synthase (dhfr-ts) knockout parasites was also able to protect I a mouse, but not in a monkey, model of L. major infection [71-73]. L. major parasites lacking the lpg2 gene were able to confer protection against homologous infection and established a chronic presence in mice without causing pathology [74]. Cross-species protection has been demonstrated in the case of an L. infantum deletion mutant lacking HSP70 type II gene that was evaluated for protective efficacy against challenge with $L$. major [75•]. Administration of the mutant parasite by numerous routes to $\mathrm{BALB} / \mathrm{c}$ mice promoted the production of high levels of nitric oxide and the development of Th1 responses that were protective against $L$. major challenge. Deletion of serine protease (CP) in L. mexicana led to an attenuated strain that established only a temporary infection in mice but was capable of triggering partial protection against homologous challenge [76]. While L. donovani centrin-deleted mutants (LdCEN-/-) were viable in culture as promastigotes, they demonstrated a selective growth arrest in the amastigote stage of development and, in vitro, could not survive in human macrophages [77]. Animals inoculated with LdCEN-/mutants were protected against challenge with $L$. donovani as well as other Leishmania species [78, 79]. L. tarentolae parasites expressing the $A 2$ virulence gene have similarly been demonstrated to protect against $L$. infantum infection of mice [80].

Based on similar principles to the gene knockout-based attenuation of Leishmania parasites, another approach is the addition of suicide cassettes that lead to inducible parasite death following inoculation. It has been suggested that parasites carrying drug-sensitive cassettes could provide suitable candidates for leishmanization, with an example being the introduction of drug-sensitive genes such as Saccharomyces cerevisiae cytosine deaminase gene, which is sensitive to 5fluorocytosine [81]. Alternatively, parasites can be modified to produce biological substances that activate immune attack, such as granulocyte macrophage colony-stimulating factor [82].

While attenuated or genetically altered whole parasite vaccines offer an intriguing approach to immunization against leishmaniasis, fears that the parasite may revert to a virulent form remain. Of particular note, mutants lacking the $\operatorname{lpg} 2$ gene developed an unknown compensatory mechanism over time that allowed them to regain their ability to cause disease [83]. Thus, persistence may not be a desirable feature of a live-attenuated vaccine, and the potential emergence of compensatory mechanisms will likely be an ongoing concern of regulatory bodies that may preclude their widespread use.

\section{Naked DNA}

Immunization with naked DNA is a relatively new approach in which single or multiple genes encoding various antigens are cloned into a mammalian expression vector. Administration is through simple intramuscular injection and multiple plasmids can be combined to yield multivalent vaccines [84]. The mechanism by which DNA vaccination generates potent immune responses appears to be through the inherent adjuvant activity of the non-methylated DNA sequences that stimulate innate responses, then by replication within the host leading to the in situ expression of the encoded proteins. Compared with the more typical vaccines, it is believed that cold chain storage, delivery, and distribution in settings with limited infrastructure should be facilitated by the stable nature of the DNA molecule.

Several studies have examined the use of experimental DNA vaccines against Leishmania species. Vaccinations with DNA encoding gp63, LACK, or PSA-2 elicited antigenspecific Th1 responses and reduced lesion development in L. major-infected mice [48, 85, 86], while DNA vaccination against the parasite enzyme gamma glutamylcysteine synthetase protected mice against L. donovani infection [87]. However, a multi-antigenic DNA vaccine encoding KMPII, TRYP, LACK and gp63 did not protect dogs against L. infantum challenge [88]. 


\section{Sand Fly Salivary Proteins}

Female phlebotomine sand flies are critically required for the transmission of Leishmania in the natural setting (i.e. excluding transfer of infected blood products, etc.), with two genera transmitting Leishmania parasites to humans (Lutzomyia in the New World and Phlebotomus in the Old World). Although the saliva of sand flies and other blood-feeding insects contain potent pharmacologic components that facilitate blood meals, the immune response to saliva proteins can preclude the parasites from establishing themselves in the vertebrate host $[89,90]$. It may be that Leishmania infection persists due to the counteraction of protective versus aggravating proteins, and it has been proposed that recognition of proteins that are part of the protective response could be harnessed as vaccine candidates to limit Leishmania infection during the sand fly's blood meal.

DNA immunization with distinct salivary proteins from $P$. papatasi modulates L. major infection: while PpSP44-immunized mice aggravate the infection, PpSP15immunized mice demonstrate protection [91]. Several reports have indicated the possibility that some recombinant salivary proteins from sand flies could serve as targets for vaccine development to control Leishamania infection [92-94]. Lu. longipalpis salivary recombinant protein LJM11 (rLJM11) induces long-lasting immunity when administered to mice that results in ulcer-free protection against L. major delivered by vector bites [69•]. Interestingly, this protection is antibody independent and abrogated by depletion of CD4 T cells, indicating that protection is actively mediated by cells but not by antibody-mediated phagocytosis. Mice immunized with DNA plasmid coding LJM19, a Lutzomyia longipalpis salivary protein, were also protected against $L$. major infection [95]. Hamsters similarly immunized with LJM19 were protected from $L$. brasiliensis infection and cutaneous lesion development [96], as well as against disease development and the fatal outcome of experimental VL caused by $L$. infantum $[97,98]$.

While some sand fly salivary proteins have demonstrated good vaccine potential in preclinical settings, it is noteworthy that populations living in Leishmania-endemic regions are regularly exposed to the vector over an extended period of time and over periods of intense biting/feeding. A study examining varying exposure periods to Phlebotomus duboscqi bites followed by $L$. major infection, indicated that protection was limited to only short-term exposure to sand flies immediately before infection [99]. Alternatively, colonization of $P$. papatasi appears to modulate the outcome of L. major infection from lack of protection to protection [100, 101]. Thus, inferences based on long-term colonized populations of sand flies should be considered with caution. It is also unclear if sensitization to the sand fly proteins and boosting and presentation of delayed type hypersensitivity responses through regular exposure to bites is an acceptable byproduct of this strategy.

\section{Importance of Adjuvants and Formulation}

One caveat regarding the use of recombinant proteins within vaccines is that, alone, they generally induce only weak T-cell responses. Adjuvants are compounds that enhance the potency of the antigen-specific immune response and can be an essential component of an efficacious vaccine. A primary function of adjuvant is to appropriately bias the antigenspecific response to elicit effective and durable T-cell responses. The discovery that properly formulated toll-like receptor (TLR) agonists can stimulate Th1 immune responses has profoundly impacted vaccine development against intracellular pathogens such as Leishmania. The clinical importance of adding a TLR4 agonist to vaccine formulations, as well as the safety and efficacy of engaging TLR4, has been demonstrated during the development of MPL. Indeed, MPL is now approved and used extensively in vaccines for other indications [102]. Our first defined vaccine against leishmaniasis used L111f together with MPL formulated in an oil-inwater emulsion (MPL-SE). The L111f+MPL-SE vaccine protects mice, hamsters, and rhesus macaques, and was the first defined Leishmania vaccine to enter clinical trials [103-106].

Inclusion of adjuvant can also potentially broaden the antigen-specific responses that are elicited. As a pertinent and clinically relevant example, Cervarix is an FDAapproved prophylactic vaccine against human papillomavirus (HPV) types 16 and 18 that is formulated with MPL (a defined mixture of TLR4 agonists and antagonists obtained from the cell wall of Salmonella). The approval of Cervarix was granted in part due to the protective immunity it conferred against oncogenic HPV strains that were not contained in the vaccine. In addition, adjuvants can reduce the cost to the enduser by allowing the use of much lower quantities of protein. The appropriate selection and use of adjuvants will likely remain an important consideration for the advancement of additional leishmaniasis vaccines.

\section{Conclusions}

With the potential to generate long-term protection and interrupt transmission, vaccination holds significant promise, and may be critically required, for sustained control of the leishmaniases. However, while both protein- and DNA-based vaccines have advanced as veterinary products, only recombinant proteins have advanced as far as licensure in human vaccines. With the large number of defined antigens that have been, and continue to be, demonstrated to afford protection in animal 
models of leishmaniasis, and the continued refinement of adjuvant components and delivery systems of these vaccines, there is a strong probability that a vaccine (or even multiple vaccines) for the leishmaniases will emerge in the coming years.

\begin{abstract}
Acknowledgments The Infectious Disease Research Institute's leishmaniasis vaccine program is funded by grants from the National Institutes of Health (AI25038) and the Bill and Melinda Gates Foundation (631 and 39129). The authors would like to thank the many preclinical and clinical researchers, along with patients and volunteers, who have made invaluable contributions to this program.
\end{abstract}

\section{Compliance with Ethics Guidelines}

Conflict of Interest Malcolm S. Duthie and Steven G. Reed declare that they have no conflict of interest.

Human and Animal Rights and Informed Consent This article does not contain any studies with human or animal subjects performed by any of the authors.

\section{References}

Papers of particular interest, published recently, have been highlighted as:

- Of importance

1. Reithinger R, Dujardin JC, Louzir H, Pirmez C, Alexander B, Brooker S. Cutaneous leishmaniasis. Lancet Infect Dis. 2007;7(9): 581-96.

2. WHO. Control of the leishmanises. WHO Technical Report Series 949. Geneva: World Health Organization; 2010.

3. Zijlstra EE, Musa AM, Khalil EA, el-Hassan IM, el-Hassan AM. Post-kala-azar dermal leishmaniasis. Lancet Infect Dis. 2003;3(2): $87-98$.

4. Sundar S, Agrawal G, Rai M, Makharia MK, Murray HW. Treatment of Indian visceral leishmaniasis with single or daily infusions of low dose liposomal amphotericin B: randomised trial. BMJ. 2001;323(7310):419-22.

5. Sundar S, Jha TK, Thakur CP, Mishra M, Singh VR, Buffels R. Low-dose liposomal amphotericin B in refractory Indian visceral leishmaniasis: a multicenter study. Am J Trop Med Hyg. 2002;66(2):143-6.

6. Sundar S, Mehta H, Suresh AV, Singh SP, Rai M, Murray HW. Amphotericin B treatment for Indian visceral leishmaniasis: conventional versus lipid formulations. Clin Infect Dis. 2004;38(3): 377-83.

7. Matlashewski G, Arana B, Kroeger A, Battacharya S, Sundar S, Das P, et al. Visceral leishmaniasis: elimination with existing interventions. Lancet Infect Dis. 2011;11(4):322-5.

8. Sundar S, Chakravarty J, Agarwal D, Rai M, Murray HW. Singledose liposomal amphotericin B for visceral leishmaniasis in India. N Engl J Med. 2010;362(6):504-12.

9. Badaro R, Lobo I, Nakatani M, Muinos A, Netto EM, Coler RN, et al. Successful use of a defined antigen/GM-CSF adjuvant vaccine to treat mucosal Leishmaniasis refractory to antimony: a case report. Braz J Infect Dis. 2001;5(4):223-32.

10. Khalil EA, El Hassan AM, Zijlstra EE, Mukhtar MM, Ghalib HW, Musa B, et al. Autoclaved Leishmania major vaccine for prevention of visceral leishmaniasis: a randomised, double-blind, BCG-controlled trial in Sudan. Lancet. 2000;356(9241):1565-9.

11. Momeni AZ, Jalayer T, Emamjomeh M, Khamesipour A, Zicker F, Ghassemi RL, et al. A randomised, double-blind, controlled trial of a killed L. major vaccine plus BCG against zoonotic cutaneous leishmaniasis in Iran. Vaccine. 1999;17(5):466-72.

12. Armijos RX, Weigel MM, Aviles H, Maldonado R, Racines J. Field trial of a vaccine against New World cutaneous leishmaniasis in an at-risk child population: safety, immunogenicity, and efficacy during the first 12 months of follow-up. J Infect Dis. 1998;177(5):1352-7.

13. Bahar K, Dowlati Y, Shidani B, Alimohammadian MH, Khamesipour A, Ehsasi S, et al. Comparative safety and immunogenicity trial of two killed Leishmania major vaccines with or without BCG in human volunteers. Clin Dermatol. 1996;14(5): 489-95.

14. Sharifi I, FeKri AR, Aflatonian MR, Khamesipour A, Nadim A, Mousavi MR, et al. Randomised vaccine trial of single dose of killed Leishmania major plus BCG against anthroponotic cutaneous leishmaniasis in Bam, Iran. Lancet. 1998;351(9115):1540-3.

15. Velez ID, Gilchrist K, Arbelaez MP, Rojas CA, Puerta JA, Antunes CM, et al. Failure of a killed Leishmania amazonensis vaccine against American cutaneous leishmaniasis in Colombia. Trans R Soc Trop Med Hyg. 2005;99(8):593-8.

16. Armijos RX, Weigel MM, Romero L, Garcia V, Salazar J. Field trial of a vaccine against new world cutaneous leishmaniasis in an at-risk child population: how long does protection last? J Infect Dis. 2003;187(12):1959-61.

17. Noazin S, Khamesipour A, Moulton LH, Tanner M, Nasseri K, Modabber F, et al. Efficacy of killed whole-parasite vaccines in the prevention of leishmaniasis: a meta-analysis. Vaccine. 2009;27(35):4747-53.

18. Noazin S, Modabber F, Khamesipour A, Smith PG, Moulton LH, Nasseri K, et al. First generation leishmaniasis vaccines: a review of field efficacy trials. Vaccine. 2008;26(52):6759-67.

19. Sacks DL, Melby PC. Animal models for the analysis of immune responses to leishmaniasis. Curr Protoc Immunol. 2001; Chapter 19: Unit 19.2. doi: 10.1002/0471142735.im1902s28.

20. Scott P, Pearce E, Cheever AW, Coffman RL, Sher A. Role of cytokines and CD4+ T-cell subsets in the regulation of parasite immunity and disease. Immunol Rev. 1989;112:161-82.

21. Sypek JP, Chung CL, Mayor SE, Subramanyam JM, Goldman SJ, Sieburth DS, et al. Resolution of cutaneous leishmaniasis: interleukin 12 initiates a protective $\mathrm{T}$ helper type 1 immune response. $\mathrm{J}$ Exp Med. 1993;177(6):1797-802.

22. Heinzel FP, Schoenhaut DS, Rerko RM, Rosser LE, Gately MK. Recombinant interleukin 12 cures mice infected with Leishmania major. J Exp Med. 1993;177(5):1505-9.

23. Mougneau E, Altare F, Wakil AE, Zheng S, Coppola T, Wang ZE, et al. Expression cloning of a protective Leishmania antigen. Science. 1995;268(5210):563-6.

24. Melby PC, Yang J, Zhao W, Perez LE, Cheng J. Leishmania donovani p36(LACK) DNA vaccine is highly immunogenic but not protective against experimental visceral leishmaniasis. Infect Immun. 2001;69(8):4719-25.

25. Aguilar-Be I, da Silva Zardo R, de Souza Paraguai E, BorjaCabrera GP, Rosado-Vallado M, Mut-Martin M, et al. Crossprotective efficacy of a prophylactic Leishmania donovani DNA vaccine against visceral and cutaneous murine leishmaniasis. Infect Immun. 2005;73(2):812-9.

26. Al-Wabel MA, Tonui WK, Cui L, Martin SK, Titus RG. Protection of susceptible BALB/c mice from challenge with Leishmania major by nucleoside hydrolase, a soluble exoantigen of Leishmania. Am J Trop Med Hyg. 2007;77(6):1060-5.

27. Goto Y, Bogatzki LY, Bertholet S, Coler RN, Reed SG. Protective immunization against visceral leishmaniasis using Leishmania 
sterol 24-c-methyltransferase formulated in adjuvant. Vaccine. 2007;25(42):7450-8.

28. Goto Y, Bhatia A, Raman VS, Vidal SE, Bertholet S, Coler RN, et al. Leishmania infantum sterol 24-c-methyltransferase formulated with MPL-SE induces cross-protection against L. major infection. Vaccine. 2009;27(21):2884-90.

29. Ghosh A, Zhang WW, Matlashewski G. Immunization with A2 protein results in a mixed $\mathrm{Th} 1 / \mathrm{Th} 2$ and a humoral response which protects mice against Leishmania donovani infections. Vaccine. 2001;20(1-2):59-66.

30. Tewary P, Jain M, Sahani MH, Saxena S, Madhubala R. A heterologous prime-boost vaccination regimen using ORFF DNA and recombinant ORFF protein confers protective immunity against experimental visceral leishmaniasis. J Infect Dis. 2005;191(12):2130-7.

31. Iborra S, Soto M, Carrion J, Nieto A, Fernandez E, Alonso C, et al. The Leishmania infantum acidic ribosomal protein P0 administered as a DNA vaccine confers protective immunity to Leishmania major infection in BALB/c mice. Infect Immun. 2003;71(11):6562-72.

32. Saravia NG, Hazbon MH, Osorio Y, Valderrama L, Walker J, Santrich C, et al. Protective immunogenicity of the paraflagellar rod protein 2 of Leishmania mexicana. Vaccine. 2005;23(8): 984-95.

33. Samant M, Gupta R, Kumari S, Misra P, Khare P, Kushawaha PK, et al. Immunization with the DNA-encoding N-terminal domain of proteophosphoglycan of Leishmania donovani generates Th1type immunoprotective response against experimental visceral leishmaniasis. J Immunol. 2009;183(1):470-9.

34. Kumari S, Singh S, Saha B, Paliwal PK. Leishmania major MAP kinase 10 is protective against experimental L. major infection. Vaccine. 2011;29(48):8783-7.

35. Kushawaha PK, Gupta R, Sundar S, Sahasrabuddhe AA, Dube A. Elongation factor-2, a Th1 stimulatory protein of Leishmania donovani, generates strong IFN-gamma and IL-12 response in cured Leishmania-infected patients/hamsters and protects hamsters against Leishmania challenge. J Immunol. 2011;187(12): 6417-27.

36. Silva AM, Tavares J, Silvestre R, Ouaissi A, Coombs GH, Cordeiro-da-Silva A. Characterization of Leishmania infantum thiol-dependent reductase 1 and evaluation of its potential to induce immune protection. Parasite Immunol. 2012;34(6): $345-50$.

37. Choudhury R, Das P, De T, Chakraborti T. $115 \mathrm{kDa}$ serine protease confers sustained protection to visceral leishmaniasis caused by Leishmania donovani via IFN-gamma induced down-regulation of TNF-alpha mediated MMP-9 activity. Immunobiology. 2013;218(1):114-26

38. Ramirez L, Santos DM, Souza AP, Coelho EA, Barral A, Alonso $\mathrm{C}$, et al. Evaluation of immune responses and analysis of the effect of vaccination of the Leishmania major recombinant ribosomal proteins L3 or L5 in two different murine models of cutaneous leishmaniasis. Vaccine. 2013;31(9):1312-9.

39. Gupta R, Kumar V, Kushawaha PK, Tripathi CP, Joshi S, Sahasrabuddhe AA, et al. Characterization of glycolytic enzymes: rAldolase and rEnolase of Leishmania donovani, identified as Th1 stimulatory proteins, for their immunogenicity and immunoprophylactic efficacies against experimental visceral leishmaniasis. PLoS One. 2014;9(1):e86073.

40. Santos-Gomes GM, Rodrigues A, Teixeira F, Carreira J, Alexandre-Pires G, Carvalho S, et al. Immunization with the Leishmania infantum recombinant cyclophilin protein 1 confers partial protection to subsequent parasite infection and generates specific memory T cells. Vaccine. 2014;32(11):1247-53.

41. Abdian N, Gholami E, Zahedifard F, Safaee N, Rafati S. Evaluation of DNA/DNA and prime-boost vaccination using
LPG3 against Leishmania major infection in susceptible $\mathrm{BALB} / \mathrm{c}$ mice and its antigenic properties in human leishmaniasis. Exp Parasitol. 2011;127(3):627-36. Results indicate that LPG3 protein is highly immunogenic and a prime-boost (DNA/Protein) immunization strategy appears to be more potent than a DNA/ DNA immunization strategy. Both strategies induced significant protection against L. major infection in BALB/c mice model.

42. Guha R, Gupta D, Rastogi R, Vikram R, Krishnamurthy G, Bimal $\mathrm{S}$, et al. Vaccination with leishmania hemoglobin receptorencoding DNA protects against visceral leishmaniasis. Sci Transl Med. 2013;5(202):202-21. Immunization with HbR-DNA induced sterile protection against $L$. donovani infection in both $B A L B / c$ mice and hamsters.

43. Henriquez FL, Campbell SA, Roberts CW, Mullen AB, Burchmore R, Carter KC. Vaccination with recombinant Leishmania donovani gamma-glutamylcysteine synthetase fusion protein protects against L. donovani infection. J Parasitol. 2010;96(5):929-36.

44. Campbell SA, Alawa J, Doro B, Henriquez FL, Roberts CW, Nok A, et al. Comparative assessment of a DNA and protein Leishmania donovani gamma glutamyl cysteine synthetase vaccine to cross-protect against murine cutaneous leishmaniasis caused by L. major or L. mexicana infection. Vaccine. 2012;30(7):1357-63. Results of this study indicate that a L. donovani $\gamma G C S$ vaccine could be used to vaccinate against more than one Leishmania species but only if the recombinant protein was incorporated into non-ionic surfactant vesicles for $L$. mexicana. DNA vaccination gave transient protection against $L$. major and no protection against L. mexicana.

45. Khare P, Jaiswal AK, Tripathi CD, Joshi S, Sundar S, Dube A. Efficacy of Leishmania donovani trypanothione reductase, identified as a potent Th1 stimulatory protein, for its immunogenicity and prophylactic potential against experimental visceral leishmaniasis. Parasitol Res. 2014;113(3):851-62.

46. McMahon-Pratt D, Traub-Cseko Y, Lohman KL, Rogers DD, Beverley SM. Loss of the GP46/M-2 surface membrane glycoprotein gene family in the Leishmania braziliensis complex. Mol Biochem Parasitol. 1992;50(1):151-60.

47. Handman E, Symons FM, Baldwin TM, Curtis JM, Scheerlinck JP. Protective vaccination with promastigote surface antigen 2 from Leishmania major is mediated by a TH1 type of immune response. Infect Immun. 1995;63(11):4261-7.

48. Sjolander A, Baldwin TM, Curtis JM, Bengtsson KL, Handman E. Vaccination with recombinant Parasite Surface Antigen 2 from Leishmania major induces a Th1 type of immune response but does not protect against infection. Vaccine. 1998;16(20):2077-84.

49. Sjolander A, Baldwin TM, Curtis JM, Handman E. Induction of a Th1 immune response and simultaneous lack of activation of a Th2 response are required for generation of immunity to leishmaniasis. J Immunol. 1998;160(8):3949-57.

50. Handman E, Noormohammadi AH, Curtis JM, Baldwin T, Sjolander A. Therapy of murine cutaneous leishmaniasis by DNA vaccination. Vaccine. 2000;18(26):3011-7.

51. Russo DM, Burns Jr JM, Carvalho EM, Armitage RJ, Grabstein $\mathrm{KH}$, Button LL, et al. Human T cell responses to gp63, a surface antigen of Leishmania. J Immunol. 1991;147(10):3575-80.

52. Burns Jr JM, Scott JM, Carvalho EM, Russo DM, March CJ, Van Ness KP, et al. Characterization of a membrane antigen of Leishmania amazonensis that stimulates human immune responses. J Immunol. 1991;146(2):742-8.

53. Montoya J, Solon JA, Cunanan SR, Acosta L, Bollaerts A, Moris $\mathrm{P}$, et al. A randomized, controlled dose-finding phase II study of the M72/AS01 candidate tuberculosis vaccine in healthy PPDpositive adults. J Clin Immunol. 2013;33(8):1360-75.

54. Van Braeckel E, Desombere I, Clement F, Vandekerckhove L, Verhofstede C, Vogelaers D, et al. Polyfunctional CD4(+) T cell 
responses in HIV-1-infected viral controllers compared with those in healthy recipients of an adjuvanted polyprotein HIV-1 vaccine. Vaccine. 2013;31(36):3739-46.

55. Taylor DN, Treanor JJ, Sheldon EA, Johnson C, Umlauf S, Song L, et al. Development of VAX128, a recombinant hemagglutinin (HA) influenza-flagellin fusion vaccine with improved safety and immune response. Vaccine. 2012;30(39):5761-9.

56. van Dissel JT, Soonawala D, Joosten SA, Prins C, Arend SM, Bang P, et al. Ag85B-ESAT-6 adjuvanted with IC31(R) promotes strong and long-lived Mycobacterium tuberculosis specific $\mathrm{T}$ cell responses in volunteers with previous BCG vaccination or tuberculosis infection. Vaccine. 2011;29(11):2100-9.

57. Esen M, Kremsner PG, Schleucher R, Gassler M, Imoukhuede EB, Imbault N, et al. Safety and immunogenicity of GMZ2: a MSP3-GLURP fusion protein malaria vaccine candidate. Vaccine. 2009;27(49):6862-8.

58. Rafati S, Salmanian AH, Taheri T, Vafa M, Fasel N. A protective cocktail vaccine against murine cutaneous leishmaniasis with DNA encoding cysteine proteinases of Leishmania major. Vaccine. 2001;19(25-26):3369-75.

59. Zadeh-Vakili A, Taheri T, Taslimi Y, Doustdari F, Salmanian AH, Rafati S. Immunization with the hybrid protein vaccine, consisting of Leishmania major cysteine proteinases type I (CPB) and type II (CPA), partially protects against leishmaniasis. Vaccine. 2004;22(15-16):1930-40.

60. Bertholet S, Goto Y, Carter L, Bhatia A, Howard RF, Carter D, et al. Optimized subunit vaccine protects against experimental leishmaniasis. Vaccine. 2009;27(50):7036-45.

61. Raman VS, Bhatia A, Picone A, Whittle J, Bailor HR, O'Donnell $\mathrm{J}$, et al. Applying TLR synergy in immunotherapy: implications in cutaneous leishmaniasis. J Immunol. 2010;185(3):1701-10.

62. Duthie MS, Raman VS, Piazza FM, Reed SG. The development and clinical evaluation of second-generation leishmaniasis vaccines. Vaccine. 2012;30(2):134-41.

63. Mukhopadhyay S, Sen P, Bhattacharyya S, Majumdar S, Roy S. Immunoprophylaxis and immunotherapy against experimental visceral leishmaniasis. Vaccine. 1999;17(3):291-300.

64. Basu R, Bhaumik S, Basu JM, Naskar K, De T, Roy S. Kinetoplastid membrane protein-11 DNA vaccination induces complete protection against both pentavalent antimonialsensitive and -resistant strains of Leishmania donovani that correlates with inducible nitric oxide synthase activity and IL-4 generation: evidence for mixed Th1- and Th2-like responses in visceral leishmaniasis. J Immunol. 2005;174(11):7160-71.

65. Rafati S, Nakhaee A, Taheri T, Taslimi Y, Darabi H, Eravani D, et al. Protective vaccination against experimental canine visceral leishmaniasis using a combination of DNA and protein immunization with cysteine proteinases type I and II of L. infantum. Vaccine. 2005;23(28):3716-25.

66. Rafati S, Zahedifard F, Nazgouee F. Prime-boost vaccination using cysteine proteinases type I and II of Leishmania infantum confers protective immunity in murine visceral leishmaniasis. Vaccine. 2006;24(12):2169-75.

67. Fernandes AP, Costa MM, Coelho EA, Michalick MS, de Freitas E, Melo MN, et al. Protective immunity against challenge with Leishmania (Leishmania) chagasi in beagle dogs vaccinated with recombinant A2 protein. Vaccine. 2008;26(46):5888-95.

68. Goto Y, Bhatia A, Raman VS, Liang H, Mohamath R, Picone AF, et al. KSAC: the first defined polyprotein vaccine candidate for visceral leishmaniasis. Clin Vaccine Immunol. 2011;18(7):111824. Demonstrates the feasibility of producing a practical, costeffective vaccine capable of protecting against multiple Leishmania species (L. infantum and L. major).

69. Gomes R, Oliveira F, Teixeira C, Meneses C, Gilmore DC, Elnaiem DE, et al. Immunity to sand fly salivary protein LJM11 modulates host response to vector-transmitted leishmania conferring ulcer-free protection. J Invest Dermatol. 2012;132(12): 2735-43. Demonstrates that intradermal immunization of mice with a sand fly salivary recombinant protein induces long-lasting CD4 T cell immunity that results in ulcer-free protection against Leishmania major delivered by vector bites.

70. Kedzierski L, Curtis JM, Doherty PC, Handman E, Kedzierska K. Decreased IL-10 and IL-13 production and increased CD44hi T cell recruitment contribute to Leishmania major immunity induced by non-persistent parasites. Eur J Immunol. 2008;38(11):3090-100.

71. Titus RG, Gueiros-Filho FJ, de Freitas LA, Beverley SM. Development of a safe live Leishmania vaccine line by gene replacement. Proc Natl Acad Sci U S A. 1995;92(22):10267-71.

72. Khamesipour A, Rafati S, Davoudi N, Maboudi F, Modabber F. Leishmaniasis vaccine candidates for development: a global overview. Indian J Med Res. 2006;123(3):423-38.

73. Amaral VF, Teva A, Oliveira-Neto MP, Silva AJ, Pereira MS, Cupolillo E, et al. Study of the safety, immunogenicity and efficacy of attenuated and killed Leishmania (Leishmania) major vaccines in a rhesus monkey (Macaca mulatta) model of the human disease. Mem Inst Oswaldo Cruz. 2002;97(7):1041-8.

74. Uzonna JE, Spath GF, Beverley SM, Scott P. Vaccination with phosphoglycan-deficient Leishmania major protects highly susceptible mice from virulent challenge without inducing a strong Th1 response. J Immunol. 2004;172(6):3793-7.

75. Carrion J, Folgueira C, Soto M, Fresno M, Requena JM. Leishmania infantum HSP70-II null mutant as candidate vaccine against leishmaniasis: a preliminary evaluation. Parasit Vectors. 2011;4:150. Demonstrates that an L. infantum deletion mutant provides protection in the L. major-BALB/c infection model and appears to be a safe live vaccine as immunodeficient SCID mice, and hamsters did not develop any sign of pathology when infected with mutant parasites.

76. Saravia NG, Escorcia B, Osorio Y, Valderrama L, Brooks D, Arteaga L, et al. Pathogenicity and protective immunogenicity of cysteine proteinase-deficient mutants of Leishmania mexicana in non-murine models. Vaccine. 2006;24(19):4247-59.

77. Selvapandiyan A, Debrabant A, Duncan R, Muller J, Salotra P, Sreenivas G, et al. Centrin gene disruption impairs stage-specific basal body duplication and cell cycle progression in Leishmania. $\mathrm{J}$ Biol Chem. 2004;279(24):25703-10.

78. Selvapandiyan A, Dey R, Nylen S, Duncan R, Sacks D, Nakhasi HL. Intracellular replication-deficient Leishmania donovani induces long lasting protective immunity against visceral leishmaniasis. J Immunol. 2009;183(3):1813-20.

79. Selvapandiyan A, Dey R, Gannavaram S, Lakhal-Naouar I, Duncan R, Salotra P, et al. Immunity to visceral leishmaniasis using genetically defined live-attenuated parasites. J Trop Med. 2012;2012:631460

80. Mizbani A, Taheri T, Zahedifard F, Taslimi Y, Azizi H, Azadmanesh K, et al. Recombinant Leishmania tarentolae expressing the A2 virulence gene as a novel candidate vaccine against visceral leishmaniasis. Vaccine. 2009;28(1):53-62.

81. Davoudi N, Tate CA, Warburton C, Murray A, Mahboudi F, McMaster WR. Development of a recombinant Leishmania major strain sensitive to ganciclovir and 5-fluorocytosine for use as a live vaccine challenge in clinical trials. Vaccine. 2005;23(9):1170-7.

82. Dumas C, Muyombwe A, Roy G, Matte C, Ouellette M, Olivier $\mathrm{M}$, et al. Recombinant Leishmania major secreting biologically active granulocyte-macrophage colony-stimulating factor survives poorly in macrophages in vitro and delays disease development in mice. Infect Immun. 2003;71(11):6499-509.

83. Spath GF, Lye LF, Segawa H, Turco SJ, Beverley SM. Identification of a compensatory mutant (lpg2-REV) of Leishmania major able to survive as amastigotes within macrophages without LPG2-dependent glycoconjugates and its 
significance to virulence and immunization strategies. Infect Immun. 2004;72(6):3622-7.

84. Ulmer JB, Wahren B, Liu MA. Gene-based vaccines: recent technical and clinical advances. Trends Mol Med. 2006;12(5): 216-22.

85. Gurunathan S, Sacks DL, Brown DR, Reiner SL, Charest H, Glaichenhaus N, et al. Vaccination with DNA encoding the immunodominant LACK parasite antigen confers protective immunity to mice infected with Leishmania major. J Exp Med. 1997;186(7):1137-47.

86. Walker PS, Scharton-Kersten T, Rowton ED, Hengge U, Bouloc A, Udey MC, et al. Genetic immunization with glycoprotein 63 cDNA results in a helper $\mathrm{T}$ cell type 1 immune response and protection in a murine model of leishmaniasis. Hum Gene Ther. 1998;9(13):1899-907.

87. Carter KC, Henriquez FL, Campbell SA, Roberts CW, Nok $\mathrm{A}$, Mullen $\mathrm{AB}$, et al. DNA vaccination against the parasite enzyme gamma-glutamylcysteine synthetase confers protection against Leishmania donovani infection. Vaccine. 2007;25(22):4502-9.

88. Rodriguez-Cortes A, Ojeda A, Lopez-Fuertes L, Timon M, Altet L, Solano-Gallego L, et al. Vaccination with plasmid DNA encoding KMPII, TRYP, LACK and GP63 does not protect dogs against Leishmania infantum experimental challenge. Vaccine. 2007;25(46):7962-71.

89. Belkaid Y, Kamhawi S, Modi G, Valenzuela J, Noben-Trauth N, Rowton E, et al. Development of a natural model of cutaneous leishmaniasis: powerful effects of vector saliva and saliva preexposure on the long-term outcome of Leishmania major infection in the mouse ear dermis. J Exp Med. 1998;188(10): 1941-53.

90. Silva F, Gomes R, Prates D, Miranda JC, Andrade B, Barral-Netto $\mathrm{M}$, et al. Inflammatory cell infiltration and high antibody production in $\mathrm{BALB} / \mathrm{c}$ mice caused by natural exposure to Lutzomyia longipalpis bites. Am J Trop Med Hyg. 2005;72(1): 94-8.

91. Oliveira F, Lawyer PG, Kamhawi S, Valenzuela JG. Immunity to distinct sand fly salivary proteins primes the anti-Leishmania immune response towards protection or exacerbation of disease. PLoS Negl Trop Dis. 2008;2(4):e226.

92. Kamhawi S, Belkaid Y, Modi G, Rowton E, Sacks D. Protection against cutaneous leishmaniasis resulting from bites of uninfected sand flies. Science. 2000;290(5495):1351-4.

93. Morris RV, Shoemaker CB, David JR, Lanzaro GC, Titus RG. Sandfly maxadilan exacerbates infection with Leishmania major and vaccinating against it protects against $\mathrm{L}$. major infection. J Immunol. 2001;167(9):5226-30.

94. Valenzuela JG, Belkaid Y, Garfield MK, Mendez S, Kamhawi S, Rowton ED, et al. Toward a defined anti-Leishmania vaccine targeting vector antigens: characterization of a protective salivary protein. J Exp Med. 2001;194(3):331-42.
95. Xu X, Oliveira F, Chang BW, Collin N, Gomes R, Teixeira C, et al. Structure and function of a "yellow" protein from saliva of the sand fly Lutzomyia longipalpis that confers protective immunity against Leishmania major infection. J Biol Chem. 2011;286(37):32383-93.

96. Tavares NM, Silva RA, Costa DJ, Pitombo MA, Fukutani KF, Miranda JC, et al. Lutzomyia longipalpis saliva or salivary protein LJM19 protects against Leishmania braziliensis and the saliva of its vector, Lutzomyia intermedia. PLoS Negl Trop Dis. 2011;5(5): e1169.

97. Gomes R, Teixeira C, Teixeira MJ, Oliveira F, Menezes MJ, Silva $\mathrm{C}$, et al. Immunity to a salivary protein of a sand fly vector protects against the fatal outcome of visceral leishmaniasis in a hamster model. Proc Natl Acad Sci U S A. 2008;105(22):7845-50.

98. da Silva RA, Tavares NM, Costa D, Pitombo M, Barbosa L, Fukutani K, et al. DNA vaccination with KMP11 and Lutzomyia longipalpis salivary protein protects hamsters against visceral leishmaniasis. Acta Trop. 2011;120(3):185-90.

99. Rohousova I, Hostomska J, Vlkova M, Kobets T, Lipoldova M, Volf $\mathrm{P}$. The protective effect against Leishmania infection conferred by sand fly bites is limited to short-term exposure. Int $\mathrm{J}$ Parasitol. 2011;41(5):481-5.

100. Ben Hadj Ahmed S, Chelbi I, Kaabi B, Cherni S, Derbali M, Zhioua E. Differences in the salivary effects of wild-caught versus colonized Phlebotomus papatasi (Diptera: Psychodidae) on the development of zoonotic cutaneous leishmaniasis in BALB/c mice. J Med Entomol. 2010;47(1):74-9.

101. Ben Hadj Ahmed S, Kaabi B, Chelbi I, Cherni S, Derbali M, Laouini D, et al. Colonization of Phlebotomus papatasi changes the effect of pre-immunization with saliva from lack of protection towards protection against experimental challenge with Leishmania major and saliva. Parasit Vectors. 2011;4:126.

102. Garcon N, Van Mechelen M. Recent clinical experience with vaccines using MPL- and QS-21-containing adjuvant systems. Expert Rev Vaccines. 2011;10(4):471-86.

103. Skeiky YA, Coler RN, Brannon M, Stromberg E, Greeson K, Crane RT, et al. Protective efficacy of a tandemly linked, multisubunit recombinant leishmanial vaccine (Leish-111f) formulated in MPL adjuvant. Vaccine. 2002;20(27-28):3292-303.

104. Coler RN, Goto Y, Bogatzki L, Raman V, Reed SG. Leish-111f, a recombinant polyprotein vaccine that protects against visceral Leishmaniasis by elicitation of CD4+ T cells. Infect Immun. 2007;75(9):4648-54.

105. Campos-Neto A, Porrozzi R, Greeson K, Coler RN, Webb JR, Seiky YA, et al. Protection against cutaneous leishmaniasis induced by recombinant antigens in murine and nonhuman primate models of the human disease. Infect Immun. 2001;69(6):4103-8.

106. Velez ID, Gilchrist K, Martinez S, Ramirez-Pineda JR, Ashman JA, Alves FP, et al. Safety and immunogenicity of a defined vaccine for the prevention of cutaneous leishmaniasis. Vaccine. 2009;28(2):329-37. 